\title{
Accounting for local meteorological effects in the ozone time-series of Lovozero (Kola Peninsula)
}

\author{
O. A. Tarasova ${ }^{1}$ and A. Yu. Karpetchko ${ }^{2^{*}}$ \\ ${ }^{1}$ Atmosphere Physics Department, Faculty of Physics, Moscow State University, Moscow, Russia \\ ${ }^{2}$ Polar Geophysical Institute, Apatity, Russia \\ ${ }^{*}$ Present address Finnish Meteorological Institute, Sodankyla, Finland
}

Received: 20 November 2002 - Published in Atmos. Chem. Phys. Discuss.: 10 February 2003

Revised: 30 June 2003 - Accepted: 2 July 2003 - Published: 7 July 2003

\begin{abstract}
The relationship between local meteorological conditions and the surface ozone variability was studied by means of statistical modeling, using ozone and meteorological parameters measured at Lovozero $\left(250 \mathrm{~m}\right.$ a.s. $1 ., 68.5^{\circ} \mathrm{N}$, $35.0^{\circ}$ E, Kola Peninsula) for the period of 1999-2000. The regression model of daily mean ozone concentrations on such meteorological parameters as temperature, relative humidity and wind speed explains up to $70 \%$ of day-to-day ozone variability in terms of meteorological condition changes, if the seasonal cycle is also considered. A regression model was created for separated time scales of the variables. Shortterm, synoptical and seasonal components are separated by means of Kolmogorov-Zurbenko filtering. The synoptical scale variations were chosen as the most informative from the point of their mutual relation with meteorological parameters. Almost $40 \%$ of surface ozone variations in time periods of 11-60 days can be explained by the regression model on separated scales that is $30 \%$ more efficient than ozone residuals usage. Quantitative and qualitative estimations of the relations between surface ozone and meteorological predictors let us preliminarily conclude that at the Lovozero site surface ozone variability is governed mainly by dynamical processes of various time scale rather than photochemistry, especially during the cold season.
\end{abstract}

\section{Introduction}

Surface ozone levels and its changes are of great interest since harmful effects of $\mathrm{O}_{3}$ and positive trends of its concentration were established at a number of northern hemispheric locations (Scheel et al., 1997; Roemer, 2001). Since many processes are affecting the ozone concentrations, it is difficult to isolate long-term ozone changes connected to changes

Correspondence to: O. A. Tarasova

(Otarasova@yandex.ru) in the chemical composition of the atmosphere from changes driven by meteorological processes of different time scales from global climate changes to local processes of ozone generation and destruction in the frontal systems.

Chemical ozone generation and deposition on the surface are known to be strongly affected by meteorological conditions. For example, ozone levels tend to be higher under hot, sunny conditions favorable for photochemical ozone production in the presence of precursors. At the same time higher temperatures cause convection to develop, which in turn can enhance vertical ozone transport. Conversely, wet, rainy weather with high relative humidity is typically associated with the low ozone levels provided by less intensive photochemical production and, possibly, by ozone deposition on water droplets (Lelieveld and Crutzen, 1990). Windy weather can influence ozone concentration near the surface in a different way. In particular, strong wind reflects the increased intensity of the vertical transport. If the boundary layer acts as a source of ozone due to chemical generation, the growth of the wind speed leads to the decrease of ozone concentration because of the vertical mixing. Conversely, if the ozone chemical budget in the boundary layer is negative, vertical transport transfers ozone-rich air from aloft downward, and surface ozone concentrations correlate positively with the wind speed.

An investigation of the influence of local meteorological conditions on the surface ozone for a particular site through in situ photochemistry, deposition and local vertical transport by convection is complicated by large-scale horizontal advection. Air masses with different history possess different ozone concentrations. For example, Moody et. al., (1995) found that up to $50 \%$ of spring-time surface ozone day-today variations on Bermuda can be explained by changes of transport patterns. Also it was shown that the long-range transport patterns changes may be responsible for surface ozone trends in the remote regions (Tarasova et al., 2003). At Lovozero, differences in transport patterns explains up to

(c) European Geosciences Union 2003 
$30 \%$ of ozone variability, with highest ozone values associating with ozone transport from industrial areas from southwest and lowest values associating with Artic air masses from North-East (Karpetchko et al., 2001).

Although the relationship between some meteorological parameters and surface ozone has been statistically established for some sites, both in urban and remote conditions (Bloomenfield et al., 1996; Dapeng Xu et. al., 1996, Gardner and Dorling, 2000), the physical background of the statistical results is not completely understood yet. Among widely used statistical models the multilayer perception (MLP) neural network, linear regression and regression tree can be mentioned (Gardner and Dorling, 2000 and references therein). While MLP models are mostly used for the forecast aims and have low physical background, regression models are well defined in physical terms and allow the possibility to investigate impacting processes. The first attempt to use separated scales for modeling was made by Flaum et al. (1996), who used the separated seasonal component of ozone variations for a regression model creation on the basis of air temperature and dew point temperature dependence.

In this paper we present results of the investigation of meteorological effects on the surface ozone time-series from the site located in the northwestern part of Russia. Both the regression analysis of the original deseasonalized data and separation of the time scales were applied. Decomposition of the original data into the different time scale components isolates the periods which contribute mostly to the bulk correlation. This information is important for a better understanding of the processes underplaying the statistical relationships between surface ozone and meteorological parameters. The results presented here could also be of importance for the construction of a regression model of surface ozone variations.

\section{Measurements}

The Lovozero site $\left(250 \mathrm{~m}\right.$ a.s.l., $\left.68.5^{\circ} \mathrm{N}, 35.0^{\circ} \mathrm{E}\right)$ is located on the Kola Peninsula plateau on the bank of Lake Lovozero. The site was operating in the frames of European project TOR-2 (Tropospheric Ozone Research). Lovozero is situated away from strong anthropogenic pollutant sources. Only a slight influence of the industrial towns of Apatity or Monchegorsk located at the distances of $80 \mathrm{~km}$ to the southwest or $120 \mathrm{~km}$ to the west, respectively, is possible. This influence is very small during the warm periods when northern and eastern winds are prevailing. The Lovozero site is situated in the tundra region so VOC emission is also weak (Guenther et al, 1995; Guenther et al, 2000).

The climate of Kola Peninsula is specific in comparison with the other regions of Russia located at the same latitude due to its unique position between the Barents Sea with the hot Gulfstream and big continental areas at the south. The mean temperature for the period of measure- ments was $+0.9^{\circ} \mathrm{C}$. The coldest registered temperature was $-36.9^{\circ} \mathrm{C}$ and the hottest one was $+30.5^{\circ} \mathrm{C}$. During the year the coldest monthly temperatures was observed in JanuaryFebruary $\left(-10^{\circ}-15^{\circ} \mathrm{C}\right)$ while the hottest month was July (about $+15^{\circ} \mathrm{C}$ ). Relative humidity all year round was about $75-90 \%$. The site surrounding is under the stable snow cover from late October-early November till the beginning of May. Snow cover substantially reduces O3 surface deposition (Galbally and Roy, 1980). As a result, $\mathrm{O}_{3}$ deposition differs strongly between summer and winter.

Prevailing wind directions at the site location are Northern (0 Degrees), South-Eastern (150 Degrees) and North-WestWestern (285 Degrees).

The main features of the local meteorological conditions are determined by the site position north of the polar cycle so there polar day (June-mid July) and polar night (Decembermid January) are clearly observed. The temperature inversions are quite rare during summer months and occur often in winter causing weaker ozone destruction near the ground in summer than in winter. As the natural and anthropogenic emissions are low, in situ ozone production in the area surrounding the site is low.

Measurements of the surface ozone concentration were carried out in Lovozero since January 1999 up to the present. For the measurements DASIBI 1008-AH analyzer with automatic temperature and pressure corrections was used. The instrument was calibrated against the reference generator of the Laboratory of Ecological Control (St. Petersburg in 1998) and cross examined with DASIBI 1008-RS instrument. The calibration data was also verified by the similar instrument operating at the Russian ozone measuring network and by the instrument used in the international experiment TROICA (Crutzen et al., 1998). The sample uptake was 10 seconds, and the stored data resolution was $1 \mathrm{~min}$, from which hourly, daily and monthly averages were calculated.

The standard meteorological parameters with the standard resolution of 3 hours were provided by Lovozero meteorological station situated on the same Kola plateau. These include temperature, relative humidity, wind speed and direction, and precipitation. Wind direction data are available only since May 2000, so they were not included in the analysis procedure. The meteorological data were provided by Russian Hydrometeorological Service and station itself is included in Russian governmental meteorological network which supports a high quality of meteorological data.

In this paper the measurements of the surface ozone concentration from January 1999 to November 2000 were used for analysis. During this period there is a gap in data (December 1999) when the device was out of service. On the basis of the measurements several papers presenting the main features of temporal variability of the surface ozone at the site were prepared and published (Arabov et.al., 2000; Elansky et.al., 2001; Arabov et. al., 2002). Among the most interesting features the bimodal structure of hourly mean histogram can be mentioned (Fig. 1). Such a structure in the 


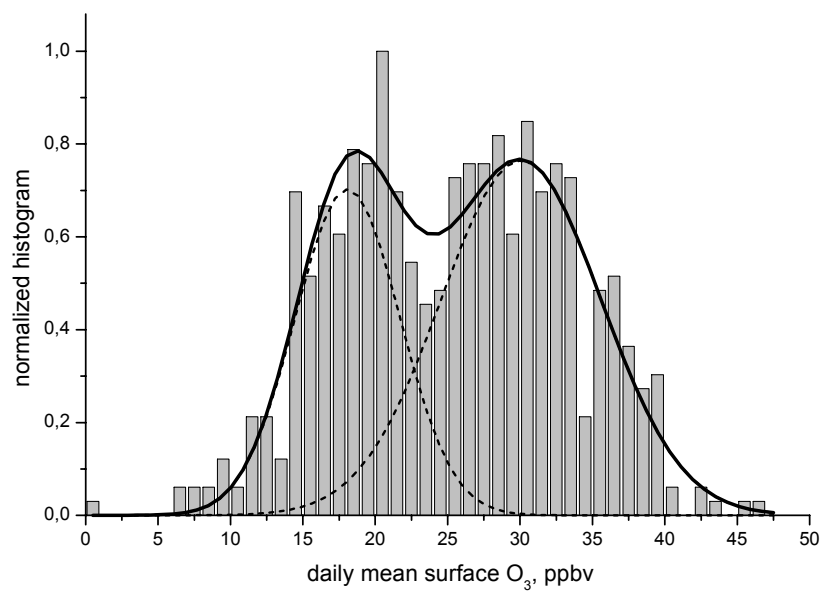

Fig. 1. Normalized histogram of daily mean surface ozone concentrations at Lovozero site for the period 1999-2000 (the Gaussian approximating functions are presented by dot lines and their sum is solid line).

concentration distribution can be partly related to the local conditions like polar days and nights and inversions absence at Lovozero site. Nevertheless the shape of the histogram remains bi-modal if daily and night conditions are separated. The changes from one regime to another probably can be attributed to the snow coverage. Histograms of hourly mean concentrations for the subsets with and without snow coverage have only one peak. But it should be understood that "snow" subsets do not contain a full seasonal cycle. There is no clear explanation of the bi-modal structure yet and additional study of this phenomenon is necessary.

The maximum hourly mean ozone value for the analyzed period was $59 \mathrm{ppbv}$ and the minimal value was 9 ppbv. The mean value of the surface ozone concentration was $26 \pm$ 9 ppbv for the period of 1999-2000. The principal feature of the seasonal variations of the surface ozone concentration at Lovozero site is the appearance of the spring maximum in April and minimum in August. The amplitude of the seasonal ozone variations was about $20 \mathrm{ppbv}$ (in 1999) and comparable with the northern Finland sites (Laurila, 1999). Similar seasonal ozone variations are observed at background European stations. In 2000 at Lovozero the secondary seasonal maximum was observed in summer and the amplitude of seasonal variations was only $12 \mathrm{ppbv}$. A possible explanation for the observed seasonal variations at the site could be stratosphere-troposphere exchange. Spatial transport features of year 2000 may cause conditions favorable for the secondary maximum formation but this phenomenon needs additional study.

Diurnal variations at the site are also typical for background locations. The highest amplitude of the diurnal variations is observed during the warm period of the year. Surface ozone concentration reaches its minimum values in the morning when ozone deposition on the surface under temper- ature inversions plays an important role. Maximum amplitude of diurnal variations is registered in summer and reaches 10 ppbv.

\section{Regression for daily mean ozone}

In this chapter we present the results of the regression modeling of the surface ozone variations related to the variability of local meteorological parameters. We chose temperature, pressure, wind speed and relative humidity as proxies for the model as they are the only available meteorological parameters. Moreover they are the usual proxies for the regression models of the surface ozone (Bloomenfield et al., 1996; Roemer, 2001) and characterize main processes driven by local meteorology like in situ photochemical production, deposition and vertical transport. Despite the fact that those parameters are not completely independent, we will consider the variables to be complementary because they influence ozone through different processes. Surface pressure was also included in the model accounting for the synoptic scale ozone variations connected with the passages of the different synoptic systems.

Like ozone there are some of the mentioned meteorological variables that have a strong seasonal cycle. Therefore the seasonal variations were removed from data series before the regression analysis. To describe the seasonal cycle the technique proposed by Zvyagintsev et al. (1996) was used. The annual component was described as a sum of sine and cosine terms both with the period of 365.25 days. However, the seasonal behavior of ozone is not a pure monochromatic oscillation, so that the semiannual component was also included into the model fitting of the seasonal cycle. In the ozone case, the sum of the annual and the semiannual components accounts for about $50 \%$ of the total day-to-day variance of ozone. The correlation coefficients between deseasonalized ozone and the meteorological parameters are presented in $\mathrm{Ta}-$ ble 1 .

It can be seen that the correlation coefficients of residuals change during the year. The ozone correlation with temperature is positive and statistically significant from winter till summer and decreases in autumn. The mechanisms driving this behavior are changes of the ozone deposition on the surface and intensity of the mixing under different convection conditions, ozone advection by the air masses from southern directions with possible in situ ozone production. These mechanisms can account only for summer and partly for spring correlations while winter relations are not clear yet. One of the possible mechanisms may be temperature inversions associated with low surface temperature and weak vertical mixing. The correlation of the ozone residuals with relative humidity is negative during all the seasons except winter, with the strongest negative correlation in autumn. The negative correlation could be related to ozone deposition on water droplets (Lelieveld and Crutzen, 1990). The 
Table 1. Correlation coefficients between the residuals of surface ozone and meteorological parameters

\begin{tabular}{ccccc}
\hline \multicolumn{4}{c}{ Correlation coefficients between surface ozone and... } \\
\hline & temperature & humidity & pressure & wind speed \\
\hline Winter & $0.48 \pm 0.08$ & $0.17 \pm 0.10$ & $-0.19 \pm 0.10$ & $0.48 \pm 0.08$ \\
Spring & $0.57 \pm 0.05$ & $-0.25 \pm 0.07$ & $-0.10 \pm 0.07$ & $0.09 \pm 0.07$ \\
Summer & $0.47 \pm 0.06$ & $-0.17 \pm 0.07$ & $0.09 \pm 0.08$ & $0.19 \pm 0.07$ \\
Autumn & $-0.15 \pm 0.07$ & $-0.38 \pm 0.07$ & $0.07 \pm 0.08$ & $0.52 \pm 0.06$ \\
Year & $0.33 \pm 0.04$ & $-0.22 \pm 0.04$ & $-0.04 \pm 0.04$ & $0.30 \pm 0.04$ \\
\hline
\end{tabular}

Table 2. Regression coefficients (with errors) and different measures of regression models effectiveness $\left(R^{2}\right.$ and $\left.d_{2}\right)$ for the residuals usage

\begin{tabular}{cccccc}
\hline & Temperature & Humidity & Wind speed & $R^{2}$ & $d_{2}$ \\
\hline Winter & $0.16 \pm 0.06$ & - & $0.58 \pm 0.21$ & 0.27 & 0.66 \\
Spring & $0.70 \pm 0.08$ & $-0.14 \pm 0.04$ & - & 0.38 & 0.72 \\
Summer & $0.64 \pm 0.09$ & - & $0.92 \pm 0.30$ & 0.25 & 0.63 \\
Autumn & $-0.35 \pm 0.09$ & $-0.13 \pm 0.05$ & $1.50 \pm 0.20$ & 0.37 & 0.72 \\
Year & $0.31 \pm 0.04$ & $-0.13 \pm 0.02$ & $0.51 \pm 0.10$ & 0.17 & 0.55 \\
\hline
\end{tabular}

correlation of ozone residuals with wind speed changes remarkably between autumn-winter and spring-summer periods. In autumn-winter correlation coefficient is about 0.5 , suggesting that ozone in the boundary layer has its origin in the free troposphere as there are no any significant sources of ozone near the ground. The small correlation coefficients in the spring-summer mean that vertical gradients of ozone are weak during this part of the year. The processes associated with the wind speed changes are strongly affected by the site's position at the latitude where the vertical exchange is intensified in the Planetary Frontal Zone and tropopause folds happen quite often (Beekmann et al., 1997). The correlation coefficient of the ozone residuals with pressure is seen to be small all the year long. It implies, probably, that the origin of the synoptical systems is more significant than the systems themselves. For example, anticyclones coming to Kola Peninsula from the south differ strongly in ozone response from the arctic ones coming from the north (Karpetchko et al., 2001). The separation of the ozone data set in accordance to the transport patterns may be necessary before surface pressure dependence can be established.

The stepwise method (which takes into consideration only the variables changing the total dispersion) for construction a multiple linear regression of the ozone concentration was used. The models were created for the complete data set and for different seasons separately. The results obtained are presented in Table 2 and Fig. 2. It can be seen that the stepwise regression method did not include the pressure into any model as it does not improve the model quality.



Fig. 2. Regression model of daily mean surface ozone on the local meteorological parameters (spring of 1999).

Two different measures of the effectiveness of the models are presented in the last two columns of Table 2. The first one is the determination coefficient $\left(R^{2}\right)$ which indicates how much of variability in the observed data is being reproduced by model. A more useful measure (Gardner and Dorling, 2000) of the model performance is provided by the "index of agreement" which is defined as

$d_{\alpha}=1-\frac{\left[\sum_{i=1}^{N}\left|P_{i}-O_{i}\right|^{\alpha}\right]}{\left[\sum_{i=1}^{N}\left(\left|P_{i}-\bar{O}\right|+\left|O_{i}-\bar{O}\right|\right)^{\alpha}\right]}$

where $P_{i}$ and $O_{i}$ are modeled and observed concentrations. The index of agreement can be calculated for both $\alpha=1$ and 2. Both values of $d_{\alpha}$ are normalized and indicate the extent that predicted deviations differ from the observed deviations about the mean observed value, indicating the degree to which model predictions are error free. Statistics $d_{2}$ is more sensitive to the model quality than $d_{1}$ since it is based on simple differences rather than squared differences..

The regression coefficients for the complete data set are presented at the bottom of the table. It can be seen that this model is not very effective because the determination coefficient reaches only 0.17 . Such a low effectiveness of the model originates, probably, from the fact that processes governing the relations between ozone and meteorological parameters differ significantly during the year and can even change sign (see Table 1).

Table 2 shows that the seasonal models fit the observations better. Meteorological parameters have the strongest impact on the surface ozone concentration in spring and autumn explaining $38 \%$ and $37 \%$ of the ozone variance, respectively. The complete model was made as a combination of the seasonal regressions into one so that the corresponding seasonal regression coefficients $K_{T}\left(s_{i}\right), K_{H}\left(s_{i}\right), K_{W}\left(s_{i}\right)$ 


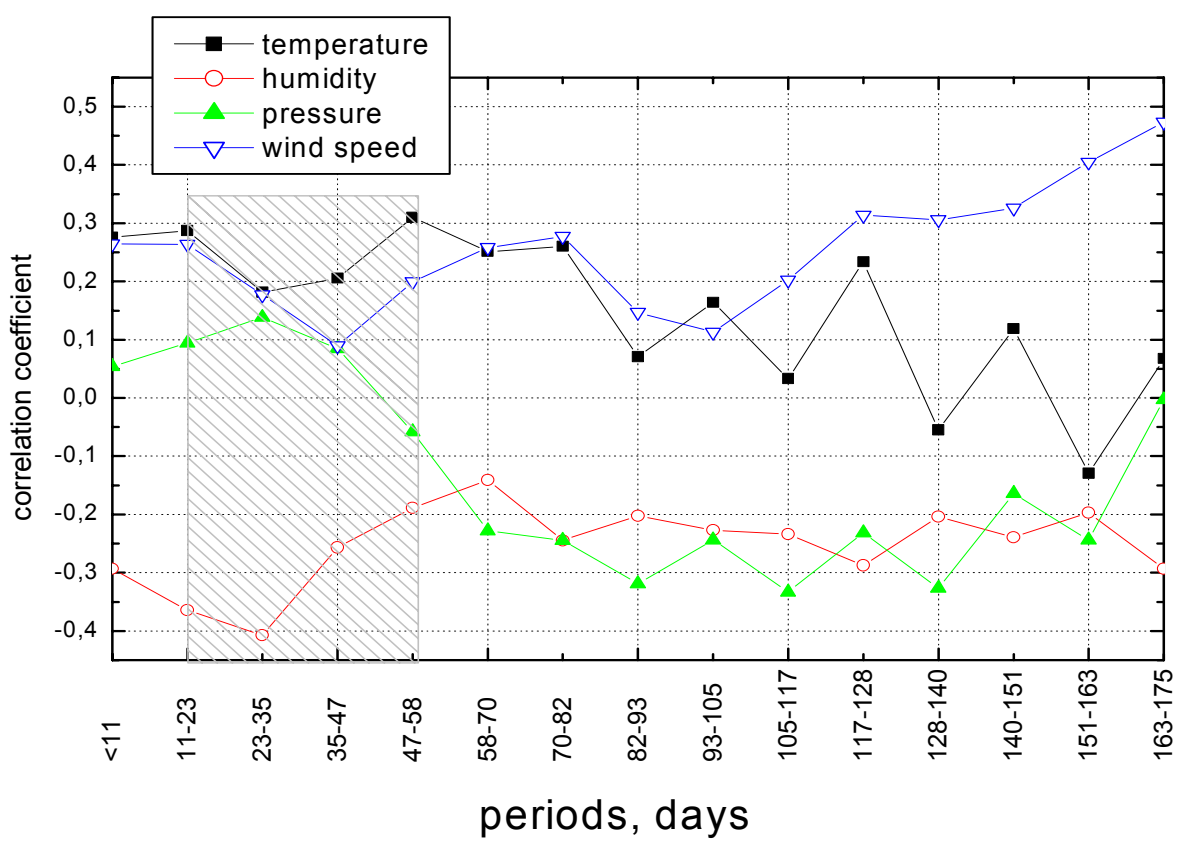

Fig. 3. Correlation coefficients for the separated scales of surface ozone and meteorological parameters variations (synoptical periods are shadowed).

with $i=1 \ldots 4$ are different for each season. The resulting model can explain about $32 \%$ of the ozone variance. This shows that seasonal model is almost twice more effective than the model without consideration of the seasonal dependence of the regression coefficients. The higher effectiveness of the seasonal model may be explained by the changes of the prevailing meteorological processes which impact the surface ozone concentration for the different seasons. Taking into account the model of seasonal ozone cycle, the surface ozone concentration $C_{\mathrm{O}_{3}}(d)$ can be expressed in the following form:

$$
C_{\mathrm{O}_{3}}(d)=C_{\mathrm{O}}+\sum_{i}\left[A_{i} \cos (2 \pi d / T)+B_{i} \sin (2 \pi d / T)\right]+
$$$$
K_{T}^{*} T(d)+K_{H}^{*} H(d)+K_{W}^{*} W(d)+R(d),
$$

where $C_{0}$ is a constant, the sum within parenthesis describes the seasonal cycle, which includes annual and semiannual components, $K_{T}, K_{H}, K_{W}$ are corresponding regression coefficients with the residuals of temperature $T(d)$, humidity $H(d)$ and wind speed $W(d)$, and $R(d)$ are ozone residuals after the regression on the meteorological parameters application, and d corresponds to the day of the year. This model explains about $70 \%$ of the total variance of the surface ozone concentration.

The results of two models with season-dependent and constant coefficients are presented in Fig. 2. To show the capability of the models to capture day-to-day ozone variations, three months of the spring of 1999 are presented in the plot. It can be seen that the model with season-dependent coefficients fits the observations better.

\section{Time scales separation}

It is of importance to estimate how the relations between surface ozone variations and meteorological parameters change on different time scales.

Time scale separation can be reached by the application of different filters (Randel, 1994; Marple, 1990). It was shown that the simplest way to reach a suitable degree of time scales separation is Kolmogorov-Zurbenko $(K Z)$ filtering (Rao et al., 1997). Other filters can also be applied (Roemer and Tarasova, 2002), but they are not so efficient in the wide range of frequencies. Another advantage of $K Z$ method is its non-sensitivity to the gaps in the original data sets.

The $K Z$ filter is based on the running average calculation, applied to the time series several times. The output of the previous step serves as an input for the next step. Repeated application of the filter provides the necessary noise suppression. The details of the filter characteristics can be found in Rao et al.(1997).

To indicate the most informative part of the spectrum, which provides the maximum response in the ozone concentration on the meteorological conditions changes, the following procedure was applied: $K Z$ filtering with the step of 3 points was applied subsequently to the time-series of the original ozone measurements and to the meteorological parameters. This yielded several separated data sets. Despite the high degree of correlation between the separated time scales of each component, the correlation coefficients of the separated ozone and meteo parameters change substantially for each scale. The changes of the correlation coefficients for 
Table 3. "Signal/noise" ratio in the power spectrum of the separated components

\begin{tabular}{ccccccc}
\hline Component & ozone & $\ln \left(\mathrm{O}_{3}\right)$ & relative humidity & temperature & wind speed & pressure \\
\hline Seasonal & 9.96 & 4.52 & 4.51 & 13.68 & 1.92 & 0.085 \\
Synoptical & 3.94 & 4.42 & 3.16 & 5.56 & 2.68 & 5.67 \\
Short & 2.43 & 2.92 & 4.46 & 1.95 & 5.01 & 1.58 \\
\hline
\end{tabular}

the different periods ranges are presented in Fig. 3. The correlations at the longest possible periods present the "natural correlations" of the seasonal variations. Maximum correlation coefficients in the range of shorter periods are observed for humidity/ozone relations at the periods of 23-35 days, temperature/ozone relations at the periods of 47-58 days and wind speed/ozone relations at the periods of 11-23 days. So the most informative part of the spectrum from the point of the mutual correlations between surface ozone and meteorological parameters lays in the range of the short periods between 11 days and 2 months. This resulted in the following approach.

As the time series of the measurements is available only for 2 years, the following decomposition is applied:

$$
\begin{aligned}
& S H(t)=\mathrm{O}_{3}-K Z_{3,3}\left(\mathrm{O}_{3}\right) \\
& S Y(t)=K Z_{3,3}\left(\mathrm{O}_{3}\right)-K Z_{15,3}\left(\mathrm{O}_{3}\right) \\
& S E(t)=K Z_{15,3}\left(\mathrm{O}_{3}\right)
\end{aligned}
$$

where $S H(t)$ represents the short term component with the periods shorter than 11 days, $S Y(t)$ represents the synoptical scale variations from 11 days to 2 months, and $S E(t)$ represents the seasonal component. As the daily mean values are used for the scales separation there are no diurnal variations included into the short term component.

The same decomposition is applied to the time series of the meteorological parameters: daily mean temperature, relative humidity, pressure and wind speed. The separated time series of surface ozone are presented in Fig. 4.

To evaluate the quality of separation the ratio of total power of useful/noise harmonics is estimated. The ratio shows the part of the energy in the selected range of periods. The separation is quite poor for most of the components as it can be seen in Table 3. This is mainly due to the short length of the analyzed time series and short time resolution, which causes strong aliasing and ringing effects in the analyzed spectra. Comparison of the separation of the $\log$ transformed ozone and non-transformed time-series shows that the seasonal component can be isolated better by use of the non-transformed ozone filtering, while for the other components the $\log$ transformation is preferable. Table 3 also demonstrates that the best separation of the seasonal component is obtained for the parameters with the strong seasonal behavior like ozone or temperature. Poor separation of the seasonal component is observed for pressure because of the small relative value of this type of variations.
Table 4. Correlation coefficients between the separated time scales of surface ozone and meteorological parameters

\begin{tabular}{ccccc}
\hline \multicolumn{4}{c}{ correlation coefficients between surface ozone and... } \\
\hline & temperature & humidity & pressure & wind speed \\
\hline Short-term & $0.03 \pm 0.04$ & $-0.29 \pm 0.03$ & $0.05 \pm 0.04$ & $0.26 \pm 0.04$ \\
Synoptical & $0.28 \pm 0.04$ & $-0.38 \pm 0.03$ & $0.07 \pm 0.04$ & $0.22 \pm 0.04$ \\
Seasonal & $-0.44 \pm 0.03$ & $-0.4 \pm 0.03$ & $-0.57 \pm 0.03$ & $0.61 \pm 0.03$ \\
\hline
\end{tabular}

Table 5. Regression coefficients for synoptical component and model effectiveness

\begin{tabular}{cccccc}
\hline & temperature & humidity & wind speed & $R^{2}$ & $d_{2}$ \\
\hline Winter & - & $0.10 \pm 0.09$ & $1.19 \pm 0.27$ & 0.48 & 0.84 \\
Spring & $0.63 \pm 0.07$ & $-0.22 \pm 0.04$ & - & 0.42 & 0.76 \\
Summer & $0.61 \pm 0.01$ & $-0.11 \pm 0.04$ & $0.22 \pm 0.30$ & 0.36 & 0.72 \\
Autumn & $-0.52 \pm 0.09$ & $-0.12 \pm 0.07$ & $1.92 \pm 0.26$ & 0.45 & 0.78 \\
Year & $0.28 \pm 0.04$ & $-0.21 \pm 0.03$ & $0.44 \pm 0.12$ & 0.22 & 0.59 \\
\hline
\end{tabular}

\section{Regression model for the synoptical component}

The correlation coefficients between the separated components (Table 4) were compared with the ones obtained for the residuals in chapter 3. Obviously the highest correlations are observed between the seasonal courses of the separated components. Note that the correlations between ozone and temperature for the short and synoptical components are positive, and correlation coefficient is negative for the seasonal components. The correlation coefficients of the seasonal ozone component and meteorological parameters are substantially higher than for the annual residuals.

The regression model for the synoptical ozone component was created as a new approach to investigate the processes of selected time scale. The filtered ozone, temperature, humidity, wind speed and pressure time-series were used in this model. All of the parameters were processed by the same algorithm. As in the modeling of the residuals the model was compiled with seasonally dependent and independent regression coefficients. The results of modeling are shown in Fig. 5. The effectiveness of the models is presented in Table 5 . 


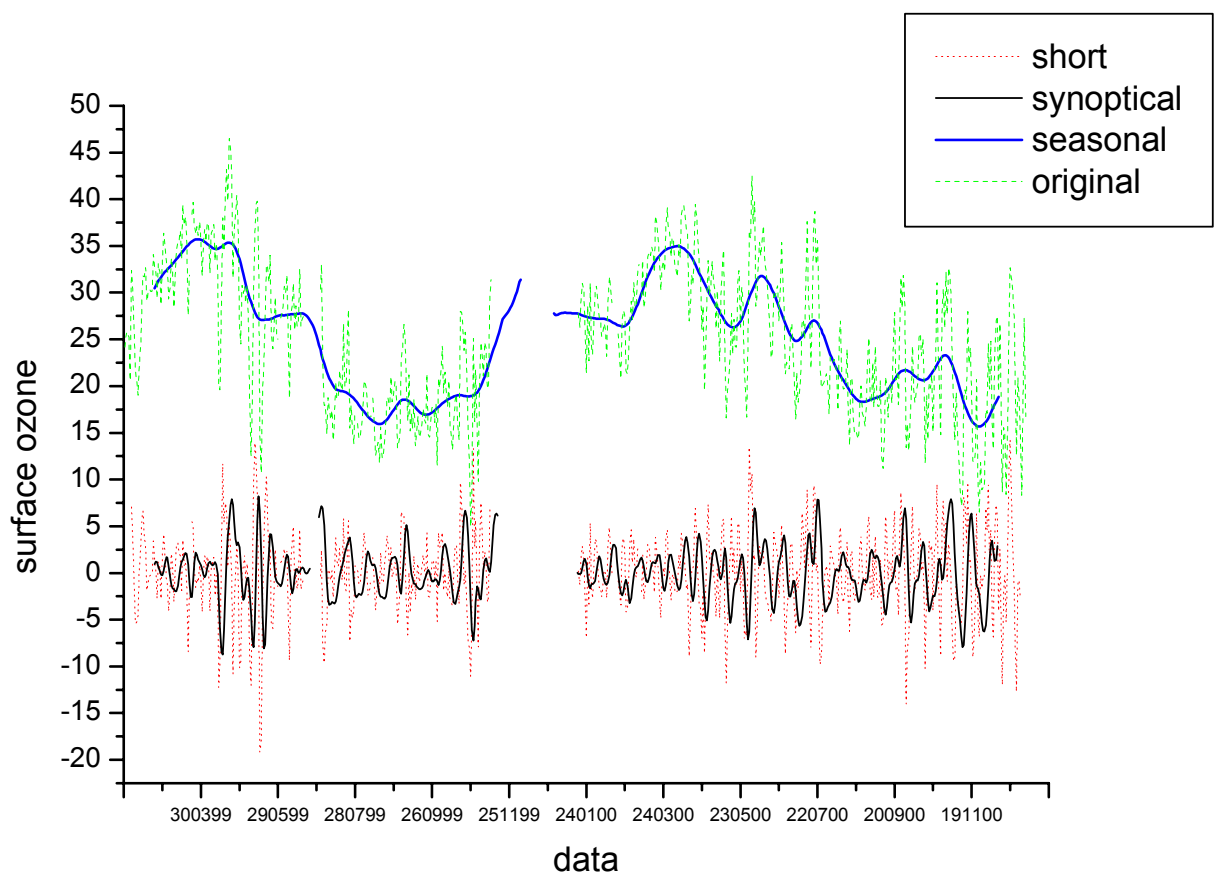

Fig. 4. Separation of the surface ozone time series.



Fig. 5. Regression models application for the ozone synoptical component.

There is a very weak dependence of the synoptical scale ozone on temperature in winter and most of the variability is caused be the wind speed changes. This relationship is much stronger than in simple regression and the mechanism of this relation is described below. The dispersion is reduced nearly by a factor of two.
The regression coefficients are very similar for the simple and synoptical scale regressions in spring. In summer the humidity impact is much stronger for the separated scales, while the wind speed influence of the synoptical ozone component is much weaker in comparison with the simple liner regression on the residuals. In autumn the temperature 
coefficient in the separated scales is larger and negative as well as in the simple regression model. This coefficient is statistically significant and very close in value for the separated scales and the simple regression model in summer and spring. Using the non-seasonal regression of synoptical scale ozone variations can explain $22 \%$ of the variability. Application of the seasonal regression shows that meteorological parameters can explain $42 \%$ of the synoptical scale variability of the surface ozone.

Comparison of the created regression models shows the following interesting features. The use of the separated scales is $30 \%$ more effective than application of the simple regression on the deseasonalized ozone time series. This is probably connected to the fact that the residuals contain not only the synoptical component, but also the short term one. It can be supposed that in the selected range of periods (1160 days) one of the most important mechanisms providing strong relation of the surface ozone variability with the meteorological parameters is Rossby and longer Waves. This type of planetary waves was registered in total ozone (Khrgian and Kuznetsov, 1981). Planetary waves provide the changes of the vertical ozone gradient in the lower troposphere which may influence in the surface ozone variations. The spectral analysis of the synoptical components of ozone and meteorological parameters showed the main period of about 2025 days. These periods coincide with the Rossby and some other long waves periods. Relation of parameters in the regression model may be described by the following scheme: in the boundary layer of the atmosphere temperature rises adiabatically in descending air that is enriched with ozone and has low humidity during the wave passage. This way the air parcel reaches the surface with higher temperature, higher ozone concentration, higher wind speed and lower humidity. Additional study is necessary to confirm proposed mechanism.

\section{Conclusions}

In the paper the possibilities of the description of surface ozone variability in terms of the empiric regression models on the local meteorological parameters are discussed. Two different approaches to the regression models creation are compared. The first one is based on the usage of deseasonalized time series of the surface ozone concentration and local meteorological parameters for the regression modeling. The second approach is based on the separation of time scales by means of $K Z$ filtering technique with subsequent regression model creation for the selected time scale.

On the basis of the proposed methods some of the mechanisms of the physical relations between surface ozone and meteorological predictors were clarified. Time scales separation allowed to estimate the contribution of some mechanisms to the surface ozone variability and to find out the most effective periods of mutual correlations. Such an approach gives the possibility to investigate the spatial and temporal structure of different processes contributing to the surface ozone variability.

The regression model of the ozone residuals after the subscription of the seasonal variations as parametric functions let us explain about $30 \%$ of the surface ozone variability on the basis of the local meteorological condition changes. The model including seasonal cycle can explain up to $70 \%$ of the surface ozone variability. At the same time it should be kept in mind that physical mechanisms driving the seasonal cycles of surface ozone and meteorological predictors can be different and this approach doesn't demonstrate really physically grounded relations.

As a second approach the time scale separation was applied. It was demonstrated that the highest correlation in the range of the short periods is observed between 11 days and 2 months. Three components separation for ozone and local meteorological parameters (temperature, relative humidity, pressure and wind speed) was performed. The synoptical scale variations were chosen for the regression modeling as the most informative in the cross correlations of the surface ozone variations and local meteorological parameters.

The regression model of the synoptical scale ozone component on the meteorological parameters can explain about $40 \%$ of variability in terms of local meteorological condition changes of the same time scale. This model is $30 \%$ more efficient than the one on the basis of residuals since the relation between parameters is provided mainly by one separated process. This fact shows that at selected range of periods about $40 \%$ of surface ozone variability at remote site is driven by the processes having similar responses to meteorological variables.

Quantitative and qualitative estimations of the relation between surface ozone and meteorological predictors let us preliminarily conclude that at least at a certain location (Lovozero site) surface ozone variability is governed mainly by dynamical processes of different time scales rather than photochemistry, especially during the cold season .

Acknowledgements. The work is carried out under the support of Russian Foundation for Basic Research (grant N 00-05-64742, 02-05-64114, 03-05-64712) and INTAS (grant N 01-0016). The authors gratefully thank Hans-Eckhart Scheel (Forschungzentrum Karlsruhe, IMK-IFU, Germany) and Dr. Gennady I. Kuznetsov (Moscow State University) for the helpful comments during manuscript preparation and all the personnel working at the site for data acquisition (the laboratory of M.I. Beloglazov, Polar Geophysical Institute, Russia).

\section{References}

Arabov, A. Yu. Beloglazov, M. I., Elansky, N. F., Karpetchko, A. Yu., Kortunova, Z. V., Kuznetsov, G. I., Povolotskaya, N. P., Senik, I. A., Tarasova, O. A.: The features of the surface ozone variation above European Russia, Physical Problems of Ecology 
(Ecological Physics), Trukhin, V. I., Pirogov, Yu. A., Pokazeev, K. V. (Eds), Moscow, MAX Press, 9, 56-69, 2002.

Arabov, A. Yu., Elansky, N. F., Olshansky, D. I., Senik, I. A., Beloglazov, M. I., Karpetchko, A. Yu., Kuznetsov, G. I., Tarasova, O. A., Kortunova, Z. V., Povolotskaya, N. P.: The temporal and spatial variations of surface ozone as observed at several sites of Russia, Atmospheric Ozone, Proceedings of the Quadrennial Ozone Symposium, HASDA, 679-680, 2000.

Beekmann, M., Ancellet, G., Blonsky, S., De Muer, D., Ebel, A., Elbern, H., Hendricks, J., Kowol, J., Mancier, C., Sladkovic, R., Smit, H. G. J., Speth, P., Trickl, T., and Van Haver, Ph.: Regional and global tropopause fold occurrence and related ozone flux across the tropopause, J.Atmos.Chem., 28, 29-44, 1997.

Bloomenfield, P., Royle, J. A., Stainberg, L. J., and Qing, Y.: Accounting for meteorological effects in measuring urban ozone levels and trends, Atm. Envir., 30 (17), 3067-3077,1996.

Crutzen, P. J., Elansky, N. F., Hahn, M., Golitsyn, G. S., Brenninkmeijer, C. A. M., et al.: Trace gas measurements between Moscow and Vladivostok using the Trans-Siberian railroad, J.Atmos.Chem., 29, 179-194, 1998.

Elansky, N. F., Arabov, A. Ya., Senik, I. A., Kuznetsov, G. I., Tarasova, O. A., Beloglazov, M. I., Karpechko, A. Yu., Kortunova, Z. V.: The Features of Surface Ozone Variations in Remote, Rural and Urban Regions of Russia, TOR-2 Annual Report 2000, ISS, Munich Germany, 72-76, 2001.

Flaum, J. B., Rao, S. T., and Zubenko, I. G.: Moderating the influence of Meteorological Conditions on Ambient Ozone Concentrations, J. Air \& Wast Manage.Assoc., 46, 35-46, 1996.

Galbally, I. E. and Roy, C. R.: Destruction of ozone at the earth's surface, Q.J.R. Meteorol. Soc., 106, 599-620, 1980.

Gardner, M. W. and Dorling, S. R.: Statistical surface ozone models: an improved methodology to account for non-linear behaviour, Atmos. Envir., 34(1), 21-34, 2000.

Guenther, A., Geron, C., Pierce, T., Lamb, B., Harley, P., and Fall, R.: Natural emissions of non-methane volatile organic compounds, carbon monoxide, and oxides of nitrogen from North America, Atmos. Envir, 34 (12-14), 2205-2230, 2000.

Guenther, A., Hewitt, N., Erickson, D., Fall, R., Geron, C., Greadel, T., Harley, P., Klinger, T.,Lerdau, M., McKay, W., Pierce, T., Scholes, B., Streinbrecher, R., Tallamraju, R., Taylor, J., and Zimmerman, P.: A global model of natural volatile organic compounds emissions, J.Geophys.Res., 100, 8873-8892, 1995.

Hogrefe, C., Rao, S., Xurbenko, I., and Porter, S.: Interpreting the information in ozone observations and model predictions relevant to regulatory policies in the Eastern United States, Bulletin of the American Meteorological Society, 81, 2083-2106, 2000.
Karpetchko A. Yu., Elansky, N. F., Kuznetsov, G. I., Tarasova, O. A., Beloglazov, M. I., Rumyantsev, S. A.: The role of air transfer processes in the formation of surface ozone concentration fields over the Kola Peninsula, Izvestiya of Russian Academy of Science, Series Physics of the Atmosphere and Ocean, 37 (5), 692 699, 2001.

Khrgian, A. H. and Kuznetsov, G. I.: The problem of atmospheric ozone observations and investigations, Moscow University Press, 216, 1981.

Laurila, T.: Observational study of transport and photochemica formation of ozone over northern Europe, J.Geophys.Res., 104 (D21), 26 235-26 243, 1999.

Lelieveld, J. and Crutzen, P. J.: Influence of cloud and photochemical processes on tropospheric ozone, Nature, 343, 227-233, 1990.

Marple Jr. S. R.: Digital spectral analysis with applications, Moscow, Mir, 584, 1990.

Roemer, M. and Tarasova, O.: Methane in The Netherlands - An exploratory study to separate time scales, TNO report R 2002/215, The Netherlands, 2002.

Moody, J. L., Oltmans, S. J., Levy, II H., Merrill, J. T.: Transport climatology of tropospheric ozone: Bermuda, 1988-1991, J. Geophys. Res., 100 (D4), 7179-7194, 1995.

Randel, W. J.: Filtering and data processing for time series analysis, Methods of experimental physics, 28, 283-311, 1994.

Rao, S., Zurbenko, I., Neagu, R., Porter, S., Ku, J., and Henry, R.: Space and Time Scales in Ambient Ozone Data, Bulletin of the American Meteorological Society, 78, 2153-2166, 1997.

Roemer, M.: Trends of ozone and related precursors in Europe, Status report, TOR-2, Task group 1, TNO-report No. R-2001/244, 2001.

Scheel, H., Ancellet, G., Areskoug, H., et al.: Spatial and temporal variability of tropospheric ozone over Europe, In: Tropospheric ozone research: tropospheric ozone in the regional and sub-regional context, Hov, Ø, Springer Verlag, Berlin, 35-45, 1997.

Tarasova, O. A., Elansky, N. F., Kuznetsov, G. I., Kuznetsova, I. N., Senik, I. A.: Impact of Air Transport on Seasonal Variations and Trends of Surface Ozone at Kislovodsk High Mountain Station, J. Atmos. Chem., (in press), 2003.

$\mathrm{Xu}$, D., Yap, D., and Taylor, P. A.: Meteorologically adjusted ground level ozone trends in Ontario, Atm. Envir., 30 (7), 1117 1124, 1996.

Zvyagintsev, A. M. and Kruchenitski, G. M.: Empirical model of surface ozone concentration near Moscow (Dolgoprudni), Izvestiya of RAS, Atmosphere and ocean physic, 32 (1), 96-100, 1996. 